- block out the sun and less problematic techniques, such as removing carbon dioxide from the atmosphere.

The CBD set a precedent for such language in 2008, when it called for a halt to ocean fertilization activities but allowed small-scale research projects to continue. That ban caused the German government to suspend an ocean fertilization experiment, dubbed LOHAFEX, in the Southern Ocean in early 2009, although the project eventually went forward. Pat Mooney, executive director of ETC Group, an environmental activist organization based in Ottawa, Canada, that lobbied for the geoengineering ban, says the issue was advanced by representatives from all parts of the globe, including Norway, Switzerland, Bolivia and the Philippines. "It won't stop small experiments, but governments will think twice before they allow anything on a larger scale," Mooney says.

David Keith, a geoengineering researcher at the University of Calgary in Canada, says he agrees with the basic message that smallscale research should move forward, but large-scale technology deployment should be put on hold. Keith commissioned a separate report, also released on 29 October, that explores in detail the costs of injecting sulphur into the upper atmosphere to deflect sunlight. The report suggests that a small fleet of specially designed aircraft could inject 1 million tonnes of sulphur into the stratosphere for just US $\$ 1$ billion- $\$ 2$ billion a year. That would offset more than half of the global warming so far caused by anthropogenic greenhouse gases, and could be scaled up. "It is certainly the first time anybody has got serious about this," says Keith, who paid for the study through a fund that he manages with Caldeira, and that is provided by Microsoft founder Bill Gates. Keith stresses that the goal is to get a grasp of what a geoengineering programme might actually look like, so that scientists can properly focus their investigations into impacts and consequences.

The Intergovernmental Panel on Climate Change (IPCC) is encouraging scientists to expand their geoengineering work, and is planning a meeting in June next year to discuss the scientific basis for geoengineering, its costs, impacts and side effects, and how to treat the issue in the next IPCC assessment. Ottmar Edenhofer, chief economist of the Potsdam Institute for Climate Impact Research in Germany and co-chairman of the IPCC's working group on climate-change mitigation, says that commitments to reducing greenhouse-gas emissions will probably not be enough to meet widely discussed climate goals, such as limiting global warming to $1.5-2{ }^{\circ} \mathrm{C}$ over the next century.

"Geoengineering is one option, and it should be included in a portfolio of other options," says Edenhofer.

\title{
World gets 2020 vision for conservation
}

\author{
With a raft of agreements emerging from Nagoya, the next \\ step is finding the cash to move beyond the blueprint.
}

\section{BY ANJALI NAYAR IN NAGOYA, JAPAN}

$\mathrm{T}$ The world has a bold new plan to stem the loss of biodiversity, and share its benefits fairly. But the vision has not yet secured enough funding to turn it into reality.

Delegates to the Convention on Biological Diversity (CBD) summit in Nagoya, Japan, last week agreed to targets that would, if achieved, offer much greater protection for natural resources over the coming decade. During the next two years, countries say they will put into place strategies to boost the size of protected areas and restore lost habitats, based on 20 headline targets (for examples, see 'Biodiversity goals').

Although these 'Aichi targets' have broadly been welcomed as a step in the right direction by conservationists, "we still believe that much higher targets are necessary to maintain the full range of critical ecosystem services essential for human well-being", says Russ Mittermeier, president of Conservation International, an advocacy group based in Arlington, Virginia.

When the CBD came into force in 1993, it articulated three main aspirations: to conserve biodiversity; to use natural resources sustainably; and to share the commercial fruits of

\section{BIODIVERSITY GOALS}

Key 2020 targets

- Cut the rate of loss of natural habitats, including forests, by at least half

- Increase terrestrial nature reserves from $13 \%$ to $17 \%$ of the world's land area

- Increase marine and coastal nature reserves from $1 \%$ to $10 \%$ of the world's seas

- Restore at least $15 \%$ of the areas where biodiversity is classed as 'degraded'

- Safeguard at least $75 \%$ of threatened plant species in collections genetic resources, such as medicinal plants and crop strains. But signatories admitted last year that they had failed to meet their 2002 goal of reducing biodiversity decline by 2010 . They have also spent years arguing over the best way to regulate the exploitation of the world's flora and fauna.

Towards the end of the Nagoya talks, it looked as though discussion on that issue known as access and benefit sharing (ABS) - would once again result in deadlock. But hours after the conference had officially ended, negotiators emerged with the Nagoya Protocol, a subsidiary to the main convention that lays out ground rules for ABS. The protocol will come into force in signatory nations once it has been ratified by at least 50 parties.

It outlines mechanisms to ensure that developing countries with valuable genetic resources are recompensed by businesses and governments who develop products from indigenous plants and animals. The protocol focuses on products developed after the treaty takes effect, but it urges governments to pay developing countries - in cash, or through technology-transfer agreements - even if the crucial genetic material was obtained decades ago. The United Nations Environment Programme, which administers the CBD, says that one possible mechanism for reimbursing developing countries would involve putting a proportion of profits into a special fund that could be tapped to support conservation efforts or build scientific capacity.

The protocol commits countries to each set up their own national agencies to manage the system, overseen by an international 'clearing house' that will also set out detailed codes of conduct and help draw up contracts between parties. "I won't say it's a miracle that we achieved this agreement, but it is surely historic," says Mittermeier.

Japan has already promised US $\$ 2$ billion to help achieve the Nagoya targets, with smaller sums pledged by other CBD signatories, including France, Norway and the European $\rightarrow$ NATURE.COM See Nature's 'Biodiversity in crisis' issue at: go.nature.com/dpclvc Union. But governments have agreed to defer a detailed funding plan until the next convention summit in New Delhi, India, in 2012. 